\title{
El cuerpo como símbolo de lo demoníaco
}

\author{
Xavier Chinga Mármol \\ Facultad de Artes, Universidad Central del Ecuador \\ imperator-leviathan@hotmail.com
}

Recibido: 9-marzo-2018 / Aceptado: 21 - septiembre-2018

\section{Resumen:}

El presente texto es una reflexión acerca de la naturaleza del cuerpo, su significado y su interpretación simbólica que lo relaciona con lo perverso. Se hace un breve análisis desde distintas posturas y contextos donde se puede apreciar la multiplicidad de relaciones que se dan entre el cuerpo como objeto y el demonio como idea para concluir con una introspección de la obra plástica del autor, su postura ante el panorama actual de las artes y la censura que aún pervive.

Palabras clave: cuerpo, demoníaco, censura, monstruoso, impuro

\section{Abstract}

This text is a reflection on the nature of the body, its meaning and its symbolic interpretation that relates to the perverse. A brief analysis is made from different positions and contexts where one can appreciate the multiplicity of relationships that occur between the body as an object and the devil as an idea to conclude with an introspection of the author's plastic work, his position before the current panorama of the arts and the censorship that still survives.

Keywords: body, demon, censorship, monster, impurus 

lo largo de la historia del arte, el cuerpo humano ha sido una constante
en el campo de la representación y ha sufrido incontables resignificaciones
conforme a la época y latitud donde se haya desarrollado su estudio o promovido su censura.

Basta con mirar a la Grecia clásica y su extensa búsqueda por alcanzar la perfección de las proporciones, para darnos cuenta que la anatomía ha sido una constante obsesión por parte de artistas y científicos que buscaron y continúan buscando desentrañar todos sus secretos. Cabe recordar que fue en el auge de esta civilización donde se establecieron los cánones ideales que un cuerpo proporcionado debe tener, generando ya sea para bien o para mal, un paradigma al que se intenta llegar incluso hasta nuestros días, sin dejar de mencionar también, que se exaltó la anatomía masculina sobre la femenina, perpetuamente vedada.

Esta censura dada en el mundo clásico, no se puede comparar a mayores condenas y estigmatizaciones al cuerpo que se dieron en siglos posteriores. Uno de los períodos en la historia más conocidos donde el cuerpo fue satanizado, violentado y censurado, sin duda es el lapso correspondiente al medioevo, donde incluso se llegó a condenar la higiene corporal por vincularla con la vanidad.

Al respecto Georges Vigarello en su libro Lo limpio y lo sucio, nos narra la historia de Platter, un desafortunado estudiante del siglo XV que pugnaba por deshacerse de los parásitos de su cabeza y de su cuerpo lavando sus ropas en el río, pero no aseando su cuerpo.

La limpieza personal tiene como símbolo la limpieza de la ropa. La atención se dirige a las envolturas que cubren la piel. El acto de Platter, claro está, lleva la marca de la pobreza del estudiante (...) Este acto es una evocación de ciertas referencias arcaicas de la limpieza. (Vigarello, 199, pág. 59-60).

En la época actual resulta impensable el hecho de no mantener una higiene constante, incluso tomando en cuenta que las taras referentes al cuerpo no se han superado por completo, pero esta anécdota ejemplifica a la perfección el cambio constante de las percepciones respecto a lo que rodea a un individuo y a la sociedad en general. El instintivo acto de Platter por librarse de los parásitos, lo lleva a despojarse de su único atuendo y lavarlo en las aguas de un río en donde ni por asomo, se le ocurriría sumergir su cuerpo para calmar el tormento de la suciedad. Como bien menciona Vigarello, la ropa es el símbolo de la limpieza, pero también el cuerpo es un símbolo de aquello que no se puede ni se debe manipular, sin importar las condiciones en las que se encuentre.

La satanización del cuerpo no sólo está ligada a diversos cultos tanto monoteístas como politeístas, obedece a factores tan diversos como niveles sociales, grupos gene- 
racionales, ubicaciones geográficas y muchos más. Sin embargo, el aspecto que cabe resaltar es precisamente la satanización, la relación del cuerpo con el mal, con Satanás.

Remitiéndonos al origen etimológico de la palabra Satán, su significado posee un matiz importante respecto a la concepción cultural y tradicionalmente aceptada. Satan en arameo, significa adversario, pero no en el sentido sobrenatural de un espíritu maligno, sino en el significado básico de oponerse a algo o a alguien. Si tomamos como punto de referencia a la tradición bíblica, Satanás es aquel quien se opuso a los designios del creador y lo cuestionó, provocando su expulsión tras dar a conocer el fruto del Árbol de la Ciencia a los padres de la humanidad.

Esta idea del opositor sin duda requería de una imagen, el ser humano como ente visual, necesita de símbolos que representen ideas y conceptos abstractos. Es en este momento que entra la figura del artista, quien es directa o indirectamente el responsable de la creación de determinados íconos cuya difusión y popularidad, los terminan convirtiendo en auténticas identidades universales, tal es el caso de la representación del mal.

La imagen del demonio ha trascendido como ícono y como símbolo en diversas áreas, pero con particular expresividad, en el campo de las artes plásticas. En este aspecto, lo demoníaco se ha manifestado expresamente en artistas teológicos que daban rienda suelta a su imaginación al crear auténticos mutantes que plasmaban las aberraciones que el infierno tenía preparado para los pecadores. El Bosco en su obra cumbre El jardin de las delicias (1500-1510 aprox.) supo reflejar el zeitgeist ${ }^{1}$ propio de su siglo, dominado por desvaríos oníricos y criaturas espantosas que sólo podrían inspirarse en las Sagradas Escrituras, guías morales que trazaban una línea espiritual y ética por donde debían caminar los fieles.

Resulta curiosa la visión dantesca de El Bosco, alejada diametralmente de la imagen común que se posee respecto a lo demoníaco, este pintor combinó cual cirujano, diferentes partes de animales, plantas, objetos y personas, para crear entes alucinantes que podrían inspirar incontables narraciones y descripciones de cada uno de ellos. La obra de El Bosco plantea una visión anacrónica del demonio, relacionándolo con la imaginación desbordada, el caos y el delirio.

1 Expresión alemana que hace referencia al clima intelectual y cultural de una era. 


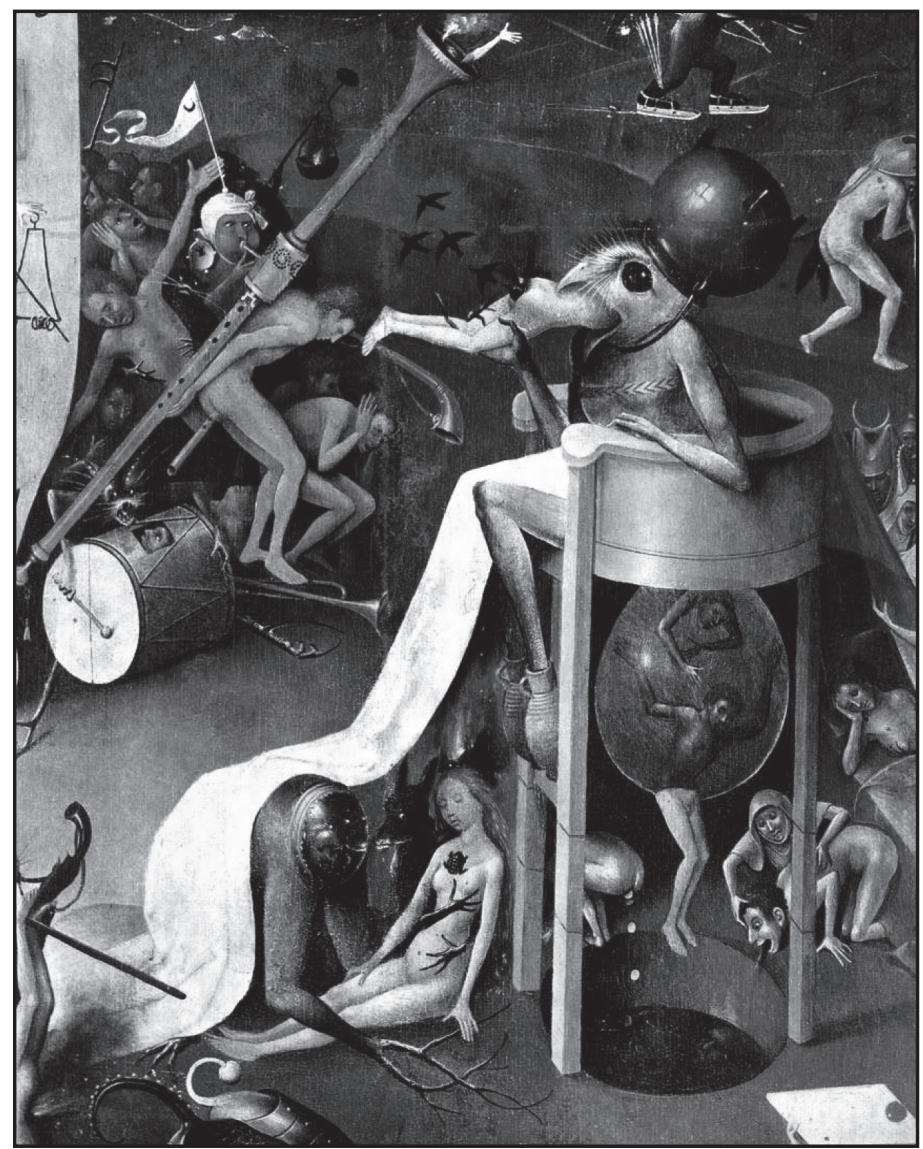

Bosch, H. (1500-1510). Infierno [fragmento]. Recuperado de: http://compostimes.com/ 2014/04/el-delicioso-jardin-de-los-deleites-adentrandonos-en-el-laberinto-i/

También es importante resaltar un aspecto importante de la visión de lo demoníaco: la seducción. Recordemos que Luzbel, el portador de luz, era el más sabio y bello de los ángeles. Su gracia e inteligencia era tal, que tuvo la capacidad de cuestionar a su creador y rebelarse ante él. Decide entregar a Eva el fruto del conocimiento del bien y del mal, fruto que desgarraría la inocencia de los primeros humanos con la luz del saber a costa de la seducción de la serpiente.

La seducción juega un papel relevante en esta parábola bíblica, pues gracias a la persuasión del demonio, Adán y Eva hacen consciencia de su desnudez y sienten vergüenza. El cuerpo ha sido demonizado por primera vez al ser apartada la niebla de la inocencia por el fruto de la sabiduría.

Condenar al cuerpo también significa condenar todo lo que proviene y surge de él, aquellas necesidades básicas como la ingesta, excreción, cópula y demás reacciones corporales, son mal vistas desde la perspectiva civilizada, justamente será un factor determinante para que la ideología imperante tome el control y subyugue la 
naturaleza animal del humano.

Para poder tener un control sobre el impulso animal del cuerpo, se supo generar y categorizar perfectamente a dos de los siete pecados capitales, la gula y la lujuria son conceptos inherentes al cuerpo físico, que denuncian los excesos carnales en dos ámbitos que provocan placer: comer y fornicar.

No es coincidencia que el placer sea vedado, la era medieval procuró borrar todo aspecto de su etapa predecesora donde dioses específicos se encargaban de guiar a los humanos a la perdición del goce. Dionisios y Afrodita, Baco y Venus, dos facetas de la naturaleza humana que la creciente fe supo desprestigiar.

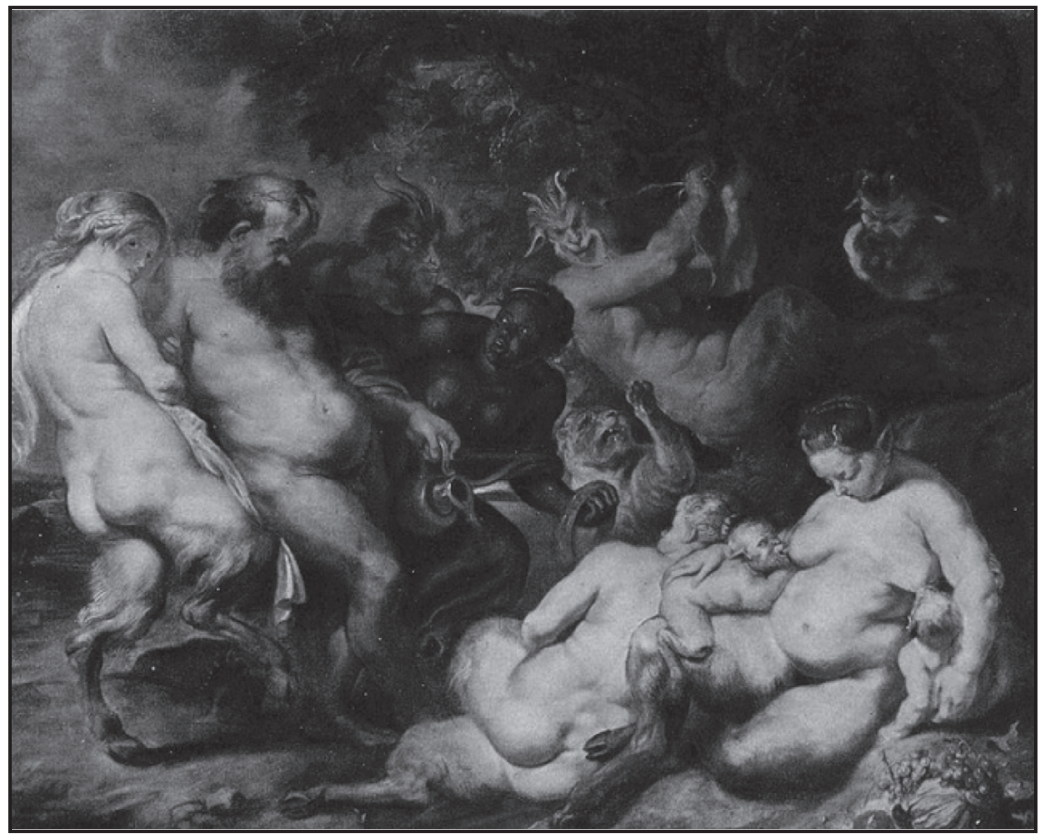

Rubens, P. (1615). Bacanal [óleo sobre lienzo]. Recuperado de: https://tamara456.blogspot.com/2014/10/bacanal-pieter-pablo-rubens.html

Sin embargo, el demonio posee un aspecto más seductor bajo la máscara de la belleza: el monstruo. Lo aterrador consigue un mayor impacto que lo voluptuoso, al respecto Enrico Castelli en su texto Lo demoníaco en el arte y su significado filosófico, nos plantea:

En todo el pensamiento medieval, la seducción de lo horrible está en la base de la influencia de lo demoníaco. Sobre la posibilidad de la seducción de lo bello no hay dudas. Lo bello seduce, pero es una seducción de poca intensidad, porque en definitiva no toca más que un determinado sentido: una mesa servida, la gula; una mujer provocativa, el sexo. (...)

Lo demoníaco desencadenado para conquistar la presa humana sabe que la máxima seducción es la de lo abismal: lo horrible. Abyssus abyssum invocat [el abismo llama al abismo]. Lo monstruoso es su aspecto más destacado. (Castelli, 2007, pág. 85). 
La cualidad de monstruoso trasciende a la imagen de un ente deforme, lo monstruoso se expresa en múltiples facetas como el horror. El cuerpo como depósito del monstruo, es un símbolo que posee diversos planos de lectura como el erotismo, la decadencia, la belleza y el peligro. José Miguel Cortés (1970) hace una acotación respecto al cuerpo como foco de riesgo.

(...) Todo aquello que hace referencia a los límites del cuerpo, que atraviesa sus fronteras (cualesquiera de sus orificios), que signifique restos corporales (de piel, uñas, pelo...), que brote de él (esputos, sangre, leche, semen, excrementos...), tiene el calificativo de altamente peligroso, de impuro. Siendo la contaminación más peligrosa la que 'se produce cuando algo que ha emergido del cuerpo vuelve a entrar en él. (Cortés, 1970, pág. 37).

El peligro que representa el cuerpo de un paciente, por ejemplo, se evidencia en las medidas preventivas que se toman para evitar posibles contagios en los centros de salud que acogen a personas enfermas. El tratamiento de sus desechos y el especial cuidado que se tiene al manejar insumos contaminados, más allá de las normas básicas de higiene, refleja la aversión natural que tiene el ser humano por mantenerse libre de enfermedad, libre de suciedad.

Un nivel mayor de rechazo a la decadencia del cuerpo, se da en la muerte. Si el contacto con un enfermo genera aversión, mucho más si se trata de un cadáver. Los gases de putrefacción generados por el proceso natural de descomposición provocan la reacción instintiva de alejarse y mantenerse fuera del ambiente malsano que rodea a un cuerpo sin vida.

La muerte, la enfermedad, el horror en general, son aspectos íntimamente relacionados con lo malévolo, con lo diabólico. Pero es en este punto donde se debe dar una visión alternativa de lo que Satán representa, en 1966 el ocultista estadounidense Anton Szandor LaVey, fundó lo que se conocerá hasta nuestros días como la iglesia de Satán. Más que una religión, es una ideología y postura filosófica basada en el individualismo, materialismo, racionalismo y darwinismo social. ${ }^{2}$ Esta peculiar filosofía ha ido ganando adeptos hasta la actualidad por diversos motivos entre los cuales destaca la lucha constante por reivindicar al individuo sobre el colectivo. Al contrario de lo que se puede pensar al escuchar su nombre, los practicantes del satanismo no son adoradores del diablo, ya que niegan la existencia de éste como un ente real, sino que toman lo que su simbología representa: inteligencia, oposición, cuestionamiento. Condenan a las religiones, sobre todo a las cristianas, y las culpan por ser difusoras de temor e ignorancia en la humanidad.

2 Ideología social que plantea la equivalencia de la teoría darwiniana de la evolución de las especies en conglomerados humanos, sustentándose en el principio de la supervivencia del más apto ante quienes no estén adaptados a una perpetua competencia. 
Toman también como referentes a todo personaje icónico de la mitología que posea una característica de rebelión y curiosidad ante el conocimiento. Prometeo es quizá el ejemplo más destacado, este titán fue condenado a un horrendo castigo por parte de Zeus debido a que entregó el fuego a los humanos, quienes estaban indefensos ante las inclemencias del mundo recién creado. Remitiéndonos a una lectura más profunda, existe un paralelismo entre el fuego y el fruto prohibido, ambos simbolizan la inteligencia y la capacidad del hombre para cuestionar a la divinidad. Prometeo y Lucifer, ambos condenados por ser portadores de la luz.

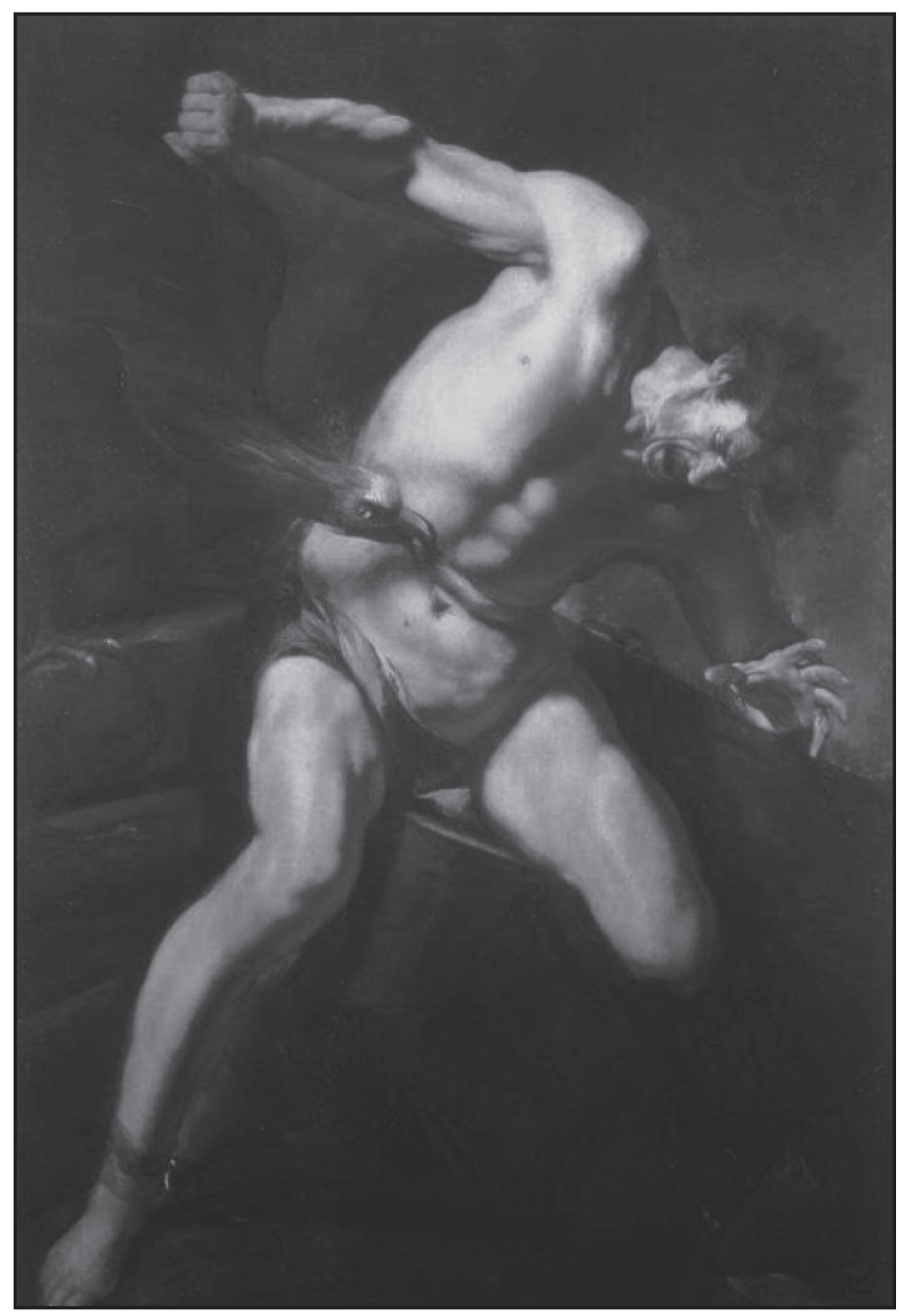

Assereto, G. (s.f.). El suplicio de Prometeo. [óleo sobre lienzo]. Recuperado de: https://euclides59.wordpress.com/tag/gioacchino-assereto/ 


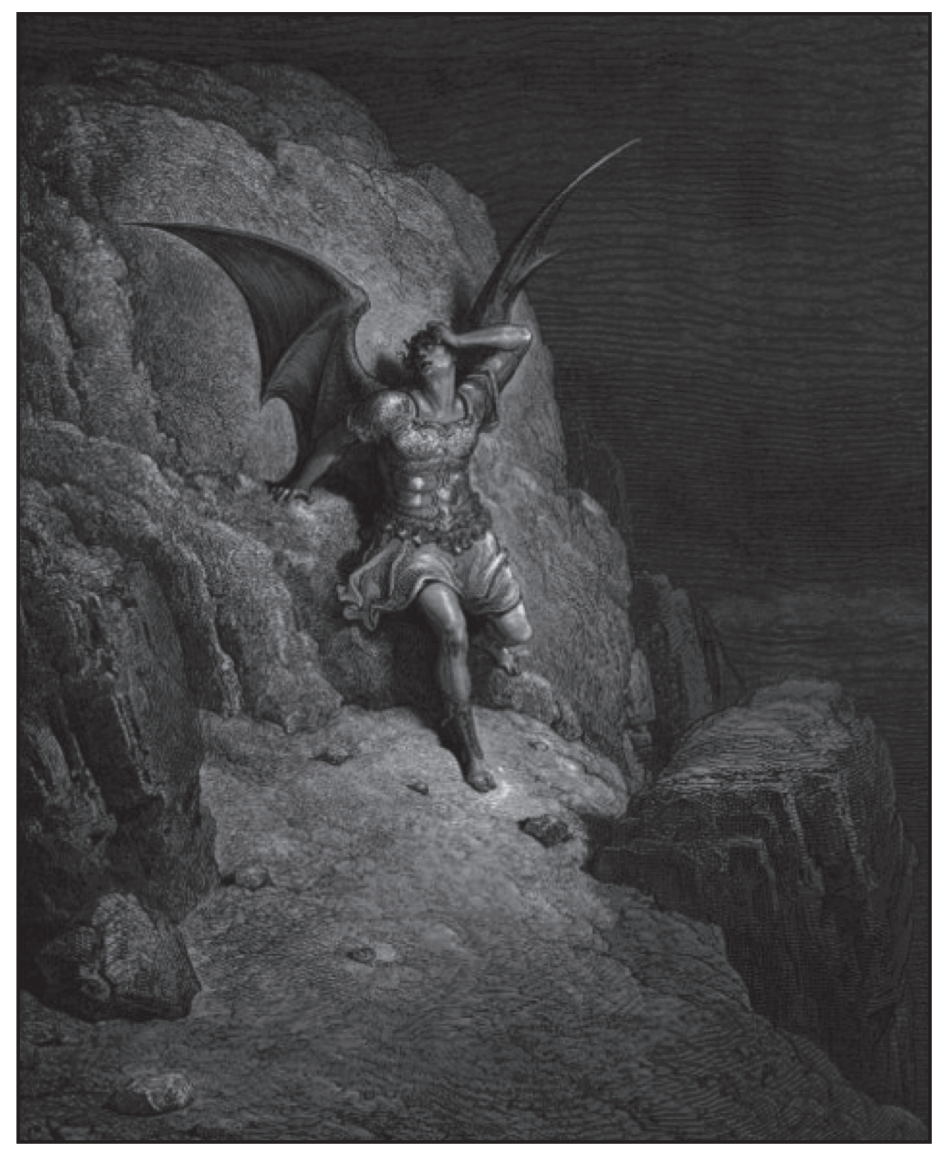

Doré, G. (1866). La caída de Lucifer. [aguafuerte]. Recuperado de: https://www.pinterest.es/pin/814729388811831421/

Tras contrastar brevemente algunas interpretaciones que ha tenido Satán en diversas épocas y bajo múltiples miradas, es importante, a modo de conclusión, hacer una reflexión sobre lo que sucede en la contemporaneidad desde la mirada del artista y cómo el cuerpo satanizado persiste en forma de censura.

La censura en nuestros días es un arma peligrosa que ha otorgado poder a varios sectores sociales (muchos de ellos minoritarios), quienes bajo la premisa de la ofensa, pueden eliminar cualquier manifestación artística, cultural o ideológica que no consideren adecuada, acorde a sus cánones morales. Es una verdadera lástima que en plena era de auge tecnológico y avances de suma importancia en el desarrollo científico del ser humano, persista una mentalidad retrógrada y victimista, aferrada a ideas caducas y malinterpretadas.

$\mathrm{El}$ arte tiene que mantenerse firme ante las presiones sociales que intenten ocultarlo, resulta inconcebible que alrededor del mundo se hagan más frecuen- 
tes las noticias de exposiciones retiradas, obras teatrales canceladas y muchas otras manifestaciones de verdadero autoritarismo por parte de instituciones de poder, pero también de conglomerados, adalides de la corrección política y de la justicia social.

El artista ahora debe asumir el papel de oponente, no sólo debe luchar y cuestionar a instituciones tradicionalmente represoras como Iglesia y Estado (que continúan perpetuando la censura en niveles más discretos), sino que también tiene la responsabilidad de poner en duda y evidencia las ideologías tóxicas que buscan controlar, entre otras cosas, la libertad creadora de quienes nos hemos decantado por el mundo de las artes y las letras.

No es tampoco una coincidencia que esta neo-censura también se relacione directamente con el cuerpo, basta constatar el riguroso control que poseen las redes sociales respecto a la imagen del desnudo, no sería mayor problema de no ser porque ahora, los diversos medios de difusión y creación de contenido en la red, representan una valiosísima herramienta para que el artista pueda compartir su trabajo con el mundo. Si bien es cierto que no todo individuo que hace arte se inclina por la representación de la desnudez, se debe pensar en quienes sí lo hacen o ¿acaso ellos no tienen el mismo derecho de difundir su trabajo sin ser castigados? ¿Acaso el arte entra en la tan vapuleada retórica de la objetificación donde todo puede ser considerado ofensivo o peligroso?

Si bien es cierto que los discursos de odio y de ofensa existen, y sin duda, son peligrosos, es también igual de importante saber identificarlos y no señalar cualquier objeto o idea que no sea del agrado de alguien que no supo mirar los hechos reales y se dejó llevar por burdos sentimentalismos propios de mentes inmaduras e irresponsables.

A lo largo de la historia, el artista ha tenido que enfrentarse a innumerables obstáculos ya sea de índole social, política, económica o cultural. Esta época no es diferente, las trabas persisten, pero con otros nombres. La libertad se pone en una peligrosa posición cuando existen ideas que se pueden y que no se pueden tratar, más aún cuando este control ideológico proviene de personas ajenas e ignorantes respecto al arte en general, personas cuyo único afán es incomodar y juzgar al otro bajo sus propios cánones corrosivos.

No queda más salida que continuar siendo el adversario, el que cuestiona y pone de manifiesto su propia inconformidad ante aquello que está causando un auténtico mal en el mundo. Y no hay mejor forma de hacerlo, que continuar creando. 


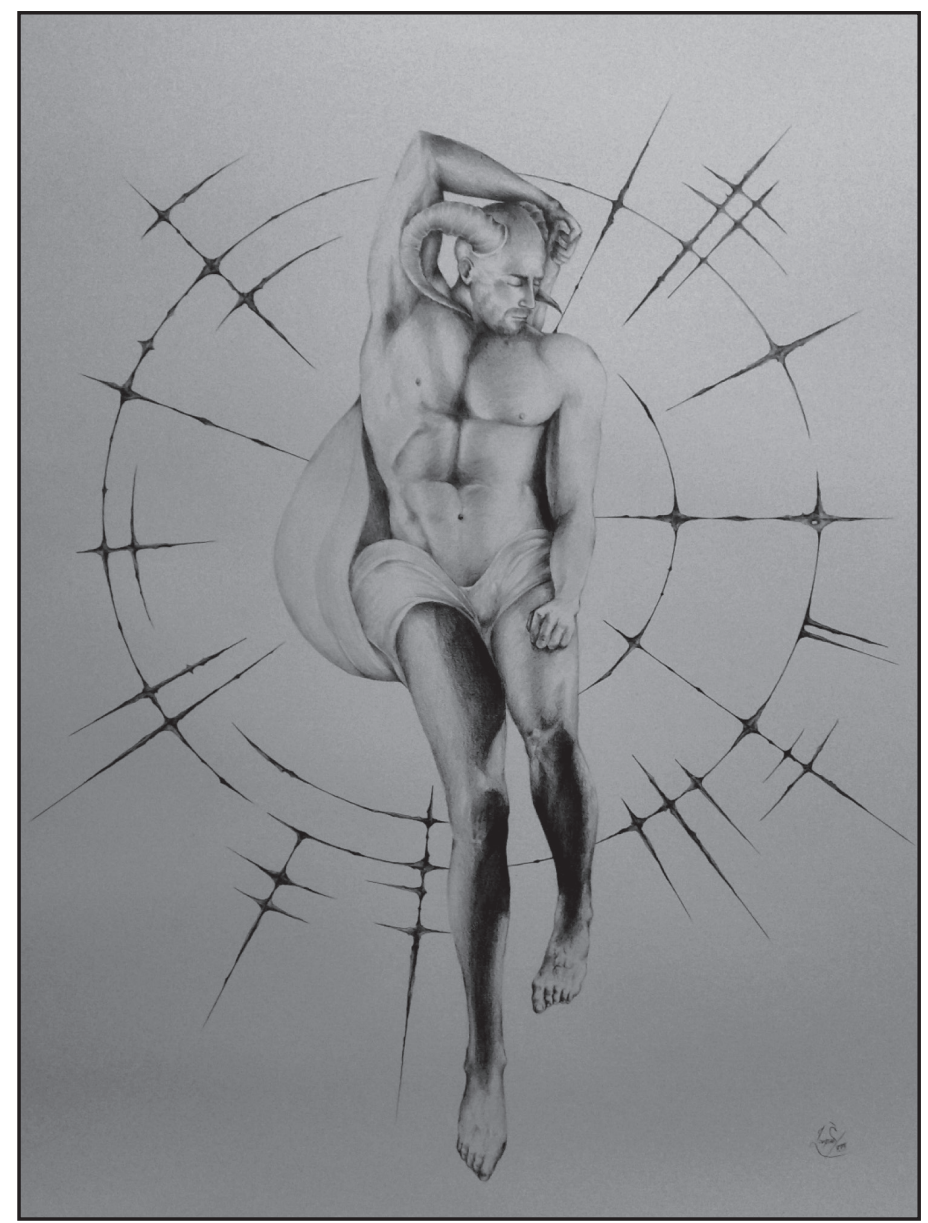

Xavier Imperator. (2016). Satyr. [grafito sobre papel]. Archivo personal

\section{Referencias}

Castelli, E. (2007). Lo demoníaco en el arte. Su significado filosófico. Madrid: Ediciones Siruela.

Cortés, J. (1970). Orden y caos. Un estudio sobre lo monstruoso en el arte. Barcelona: Anagrama.

Vigarello G. (1985). Lo limpio y lo sucio. La higiene del cuerpo desde la Edad Media. Madrid: Alianza Editorial. 
